The International Journal Of Engineering And Science (IJES)

|| Volume || 6 || Issue || 2 || Pages || PP 14-18 || 2017 ||

ISSN (e): $2319-1813$ ISSN (p): $2319-1805$

\title{
A Study of the Root Causes of High Failure Rate of Distribution Transformer - A Case Study
}

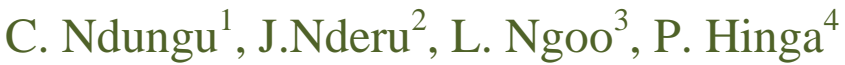 \\ ${ }^{1}$ Jomo Kenyatta University of Agriculture and Technology (JKUAT) Nairobi Kenya, \\ ${ }^{2} J K U A T$, \\ ${ }^{3}$ Multimedia University, \\ ${ }^{4} J K U A T$
}

\begin{abstract}
-
A distribution transformer is one of major electrical equipment that links the power utility and power consumers. It is what enables the power utility to supply electricity to consumers. In recent time, there has been an upsurge of distribution transformers premature failure before reaching the desired and designed service life. Consequently, the power utility has been incurring huge economical losses in replacing the faulty transformers or repairing them. On the other hand, failure of transformer inconveniencies power end users by interrupting the power supplies for prolonged period of time before the faulty transformer is replaced. In this paper, an effort is made to investigate the root causes of premature failure of distribution transformers. Research has revealed that line surges and switching transients are among the main causes of the transformers failures as this accelerates deterioration of insulation materials. This has been aggravated by lack of lightning arrestors and vandalism of low voltage and high voltage earthing systems. It is also noted that a transformer is usually 'killed' by unusual stresses that usually break down its weak insulation and hence leading to reduced transformer life. Use of concrete poles with earth wire appended is proposed to deter vandalism of earthing wire. In addition, proper fuse grading, installation of High Voltage $(H V)$ expulsion fuses and regular Operational and Maintenance $(O \& M)$ has been recommended to reduce the premature failure of distribution transformers.
\end{abstract}

Keywords: Concrete poles, Distribution transformers, earthing wire, Fuses grading, Harmonics

Date of Submission: 09 September $2016 \longrightarrow$ Date of Accepted: 25 February 2017

\section{INTRODUCTION}

A distribution transformer is an imperative link of the distribution system without which the power utility could not able to supply the electricity to end users. It is used for energy transfer through electromagnetic induction between two or more circuits. Failure of distribution transformer is devastating and costly experience because it causes an outage to the area the transformer is supplying power. In the past, distribution transformers served for more than sixty years [1, 2]. In recent years, many distribution transformers fail even a few years after commissioning. It is for this reason that many studies are being carried out to investigate the main causes of the distribution transformers premature failure. In Kenya for instance, the failure rate is approximately $10-12 \%$ per annum which is far above the failure rate of $1-2 \%$ in the developed countries per annum (as per Kenya Power reported cases of failed transformers). Due to rural and primary school electrification, Government and partnership funded projects such as Global Partnership On Output Based Aid (GPOBA), last mile, and electrification of suburb areas, the number of distribution transformers are continuously increasing. It is pertinent to address the cause of the premature failure of transformers because they are contributing to both loss of capital and revenue to the power utility and slowing down the economic growth of the country.

It has been noted that due to relative low cost of distribution transformers (as compared with power transformers), very little effort is made by utility to find out the root cause of transformer failure. Lack of investigating the root cause, could be attributed to one of the reason why more failures happen immediately or within a very short period after replacing a damaged transformer [3, 4, 5].

The research carried out by William H.B of Hartford Steam Boiler (2005) [4] has shown that transformer fail due to insulation breakdown could be contributed to electrical, mechanical and thermal factors [6]. Electrically induced factors include operation of transformer under transients or sustainable over voltage condition, exposure to lightning surges and switching surges, or partial discharge (corona) due to poor insulation system design. On the other hand, mechanically induced factors are such as looping of the inner most windings, conductor tipping, conductor telescoping and failure of coil clamping system. Thermal induced factors include degradation of cellulose insulation of oil and insulation material of the windings. Thermal induced factors are mainly due to 
overload beyond transformer design capacity as result of cold load pickup (loads transformer supplies after restoration of power after prolonged power outage), failure of transformer cooling system, operating transformer in an over excited condition (under frequency) and operating under excessive ambient temperature conditions [7, 8]. MIL-STD -1629A standards clarifies transformer faults in three categories; severity, frequency and detection factors. This give rise to priority number $(\mathrm{PN})$ which is defined as

PN $=$ Severity $*$ Frequency (occurrence)*Detection

The minimum PN of any faults on transformer is 1 and maximum is 120 . The PN for various elements of a transformer are as depicted in table 1 below [9];

Table 1: PN for various elements of a transformer (1)

Data sourced from MIL-STD-1629A

\begin{tabular}{|l|l|l|}
\hline S/no. & Failure type & PN \\
\hline 1 & Windings & $6-30$ \\
\hline 2 & Bushing & $24-48$ \\
\hline 3 & Tap-charger & $28-52$ \\
\hline 4 & Core & 6 \\
\hline 5 & Tank & 18 \\
\hline 6 & Protection system & $22-64$ \\
\hline 7 & Cooling system & $26-48$ \\
\hline
\end{tabular}

From Table 1, is evident that protection system has the highest PN (22-64). This therefore implies lack of proper protection system contribute to high failure rate of transformer. Protection system includes poor fuse grading (over-rated fuses), lack of lightning arrestors and an ineffective earthing system. Core failure is the least cause of premature failure of distribution transformer. It is worth pointing out that bushing failure is associated with poor workmanship and O\&M as is mainly caused by;

i. Loosening of conductor due to vibration

ii. Sudden over-voltage which cause partial discharge

iii. Ingress of water at seal of the transformer

iv. Not replacing old oil which may result in internal flashover

Research has shown that there are various measures which may increase the expectant life and efficiency of distribution transformers (The expected life span of transformer above 100KVA is 35 years while below 100KVA is approximately 25years). These measures include [8]; adequate and good design. Transformers manufacturer in recent time have compromised both on quality and reliability. This is achieved by lack of adequate clearance for free air circulation, economical size of winding wire which cannot withstand higher current densities due to short circuit conditions, and improper use of inter-layer papers. Enhanced O\&M to ensure oil level of the transformer is sufficient, clearing trees which are main source of high impedance fault, proper fuse grading and remove of condensed water in the transformer. Use of correct diversity factor to avert overloading of the transformer and avoiding two phasing in rural areas which causes unbalance current that raise potential of neutral with respect to the earth are some of the measures utility need to undertake to avert early failure of distribution transformers.

It has been observed that most of transformer supplying industrial and institution are premature failing. The research carried out by R. Singh and others (2014) [8] revealed that increase of non linear loads both at industries and at institutions has resulted to high harmonic content which increases the current leading to overload of transformers. It is worth noting winding copper losses $\left(\mathrm{I}^{2} \mathrm{R}\right)$, the core losses and stray losses which increase significantly operating temperature of a transformer has direct proportionality with level of harmonic frequencies present. It is important to note that, average life expectancy of the transformers is directly proportional to the average life of insulating materials. On steady state power supply, harmonics and variations in frequency are the main factors that accelerated aging of insulation materials and hence premature failure of distribution transformers $[9,10,11$ and 12]. It is for this reason a study was carried out to establish the main causes of the distribution transformer in most part of the Kenya.

\section{METHODOLOGY}

Kenya Power is the main distributor of electricity in Kenya. Currently it has a customer base of 4 million. The total number of estimated installed distribution transformers across the county are forty five thousand. The failure rate of these transformers is approximated as to be $10-12 \%$ which is far above the recommended level of 1-2\%. [3]. Table 2 shows the number of transformers that failed between April 2014 to March 2016 and their suspected cause of failure. 
Table 2: Total number of failed transformer and suspected causes.

\begin{tabular}{|l|r|r|r|r|r|r|r|r|r|r|r|r|r|}
\hline Probable Cause of Failure & \multirow{2}{*}{ April'15 } & May '15 & Jun '15 & Jul '15 & Aug '15 & Sep '15 & Oct'15 & Nov '15 & Dec '15 & Jan '16 & Feb '16 & Mar '16 & Total '15 \\
\hline Lightning Strikes & 35 & 38 & 19 & 13 & 20 & 24 & 23 & 45 & 41 & 18 & 17 & 42 & 368 \\
\hline Vandalism & 42 & 44 & 43 & 34 & 25 & 30 & 26 & 45 & 31 & 25 & 30 & 36 & 526 \\
\hline Fault on LV System & 82 & 93 & 79 & 59 & 49 & 51 & 65 & 102 & 107 & 86 & 71 & 69 & 1077 \\
\hline Broken Bushings & 8 & 18 & 6 & 11 & 10 & 15 & 12 & 8 & 6 & 12 & 8 & 4 & 152 \\
\hline Burnt/Broken Rods & 15 & 2 & 19 & 5 & 4 & 8 & 12 & 11 & 4 & 40 & 15 & 30 & 196 \\
\hline Oil Leakage & 33 & 27 & 33 & 24 & 25 & 17 & 22 & 33 & 19 & 19 & 36 & 30 & 399 \\
\hline Accidental Damage & 3 & 9 & 0 & 7 & 2 & 2 & 3 & 18 & 0 & 0 & 0 & 8 & 70 \\
\hline Overload & 24 & 44 & 13 & 40 & 7 & 15 & 21 & 26 & 26 & 18 & 12 & 12 & 331 \\
\hline Failed on Commissioning & 11 & 8 & 6 & 2 & 3 & 5 & 3 & 6 & 4 & 5 & 3 & 6 & 81 \\
\hline Internal Defects & 64 & 13 & 34 & 15 & 39 & 20 & 49 & 21 & 27 & 43 & 35 & 33 & 525 \\
\hline Total & 317 & 296 & 252 & 210 & 184 & 187 & 236 & 315 & 265 & 266 & 227 & 270 & 3725 \\
\hline
\end{tabular}

Source: Utility IMS, Network Management Division

From above Table, faults emanating from low voltage circuits were suspected to be the main cause of premature failure of distribution transformer (28.9\%). The least suspected cause was accidental damage (1.9\%). A random number of installation of transformers totalling 166 depicted in Table 3 were inspected to established the main contributors of failure on low voltage side of transformer. The data was collected in five regions namely Nairobi South, Mt. Kenya, Coast, Central Rift and Western regions as per Table 4 below.

Table 3: Transformers sampled and ratings

\begin{tabular}{|l|l|l|l|l|l|l|l|l|}
\hline Rating (KVA) & 25 & 50 & 100 & 200 & 315 & 630 & 1000 & Total \\
\hline 11KV & 12 & 22 & 25 & 40 & 27 & 1 & 4 & 131 \\
\hline 33KV & 4 & 9 & 10 & 8 & 2 & 2 & 0 & 35 \\
\hline Total & 16 & 31 & 35 & 48 & 29 & 3 & 4 & 166 \\
\hline
\end{tabular}

Table 4: Transformers sampled per region

\begin{tabular}{|l|l|}
\hline Region & No. of transformers sampled \\
\hline Nairobi South & 32 \\
\hline Western & 35 \\
\hline Mt. Kenya & 36 \\
\hline Central Rift & 31 \\
\hline Coast & 32 \\
\hline Total & $\mathbf{1 6 6}$ \\
\hline
\end{tabular}

The findings are summarized in the Table 5 below;

Table 5: Findings of inspection of sampled transformers

\begin{tabular}{|l|l|l|l|l|}
\hline Description & Yes & No & Total & Vulnerability \\
\hline Surge diverter properly installed and earthed? & 58 & 108 & 166 & $65 \%$ \\
\hline TX Body \& metallic parts earthed properly & 90 & 76 & 166 & $46 \%$ \\
\hline PME for TX (LV) properly done? & 74 & 92 & 166 & $55 \%$ \\
\hline Arcing horns properly installed? & 56 & 110 & 166 & $66 \%$ \\
\hline Availability of HV fuses (Expulsion fuses)? & 40 & 126 & 166 & $76 \%$ \\
\hline Trace encroachment? & 79 & 87 & 166 & $48 \%$ \\
\hline Poor sag along circuit? & 57 & 109 & 166 & $34 \%$ \\
\hline LV fuses properly graded? & 56 & 45 & 101 & $45 \%$ \\
\hline
\end{tabular}

Where;

PME -Protective multiple earthing, TX - Distribution Transformer, LV - Low Voltage, HV - High Voltage

From the above Table 5, it is observed that most distribution transformers are exposed heavily to lightning and switching surges as more than half of all the inspected transformers were found to lack Lightning Arrestors (LAs). The report (Table 6) also showed that most of the transformers that were within $10 \%$ of the distance from end of the feeder were most affected by high failure rate. The main cause of failure is attributed by transient travelling waves that mostly originate from switching operations of the circuit breakers during Operational and Maintenance or during the line fault double in magnitude after reflection at end of the feeder.

\begin{tabular}{|l|l|l|}
\hline $\begin{array}{l}\text { Near the Substation (Approx. } \\
\mathbf{1 0 \%} \text { From Substation) }\end{array}$ & $\begin{array}{l}\text { In the Middle of the } \\
\text { Feeder }\end{array}$ & $\begin{array}{l}\text { At End or Approx. 10\% From the } \\
\text { Terminal of the Feeder }\end{array}$ \\
\hline 12 & 21 & 23 \\
\hline
\end{tabular}


From Table 6, it is shown that lack of installation LAs on the HV side of transformer results in premature failure of the transformers as lightning strikes and transient travelling waves causes $\mathrm{HV}$ windings insulation to give in due to high surge voltages. Further, it was noted that most of the transformers arc horns were not well aligned. This was caused by poor workmanship and lack of knowledge of field marshal the purpose of the arc horns. It paramount noting that due to rampant vandalism of the earthing wire and earth rods, even properly aligned arc horns and installed surge diverters are rendered ineffective.

From the investigation, a substantial number of the transformers $(45 \%)$ had direct wire instead of graded fuses on the low voltage side. This caused the transformer to be overloaded for prolonged period of time due to high impedance fault (which may be caused by a tree branch touching a phase) or cold load pickup. The high current increases transformer thermal heating (losses) that raise windings and insulation oil temperature leading to decrease of the life of the transformer. The heat also accelerates the aging of cellulose of oil and hence lowering the degree of polymerization (DP) of solid insulation that provides dielectric and mechanical isolation of the windings [7].

\section{CONCLUSIONS}

From the study the followings were concluded;

i. It was noted that the failure rate of distribution transformers in Kenya is on upward trend and there is need to reverse the trend. Currently the failure rate is $10 \%$ against recommended $1-2 \%$ annually as per international standard.

ii. The distribution transformers are poorly protected from switching surges, voltage spikes and line faults/ flashovers.

iii. Vandalism of earthing system both for HT and LV side of the transformer expose the transformers to high voltage surges that lead to insulation breakdown resulting to early failure of the transformers

iv. Reflection of travelling wave impact negatively on the transformer causing more transformer to fail prematurely due to lack of proper protection system

v. Most of the distribution transformers are apparently replaced immediately without the technical personnel establishing the root cause of the problem. This has aggravated the transformer failure rate.

vi. High harmonic current result to transformer overload especially triplen harmonics (that circulate within delta windings) causing HV winding insulation breakdown

The authors recommend to the power utility to undertake the following measures to improve distribution transformers expectant service life and efficiency;

$\checkmark$ Avoid transformer overload by properly grading the LV fuses. Use of direct link should be avoided and discouraged. Each circuit should have independent fuses. No sharing of fuses to control more than one circuit.

$\checkmark$ Use of concrete poles with earth wire appended is recommended to deter earthing wire vandalism. Appended earth wire inside the concrete prevent vandals from accessing the earth wire hence ensuring the transformer is properly earthed both HT and LV side.

$\checkmark$ High impedance faults should be avoided by clearing flora that encroach the feeder and low voltage line wayleave. The O\&M team to frequently patrol the lines especially wet area where rate of growth of trees are high. The power utility may adopt insulated cables instead of bare conductors at rural area where trees are known to be fast growing. Use of phase separators and re-sagging loosely sagging lines can avert phase clashing that causes transformer overloading.

$\checkmark \quad$ The transformer to be properly protected by installing correct fuse rating and earthed LAs. It was observed that $76 \%$ of distribution transformer have no expulsion HT fuses hence exposing the transformer HV windings to high fault currents when a fault occurs along the feeder.

\section{REFERENCE}

[1]. Shayan Tang Jan, Raheel Afzal and Akif Zia Khan, Transformer Failures, Causes And Impact, International conference data mining, civil and mechanical engineering, February 2015

[2]. Shrikent S. Rajurkar, Jayant G and Amil R. Kulkan, Analysis Of Power Transformer Failure On Transmission Utilities, $16^{\text {th }}$ National power system conference Dec, 2010

[3]. Ambuj Kumar, Sunil Kumar Singh and Zakir Husain, Root Cause Analysis Of Transformer Failure Scenario At Power Substation, Advances in environmental and agriculture science, 2013

[4]. William H. Bartley P.E, Failure Analysis of Transformer, The Hartford Steam Boiler Inspection and insurance Co. 2005

[5]. S.N. Singh, Electrical Power Generation, Transmission and Distribution, (New Delhi, 2007, $8^{\text {th }}$ edition).

[6]. Colin Bayliss and Brian hardy, Transmission And Distribution Electrical Engineering, $\left(2008,3^{\text {rd }}\right.$ edition)

[7]. Ranjane Singh, A.S Zadgaonker and Amarjit Singh, Premature Failure Of Distribution Transformer- A Case Study, IJS\&ER Vol. 5 issue 6, June 2014

[8]. Ranjane Singh, A.S Zadgaonker and Amarjit Singh, Impact Of Harmonics On Distribution Transformer Supplying A Technical Institution - A Case Study, Journal of research in electrical and electronic engineering (ISTP-JREEE), 2010 
[9]. IEEE C57.125, A Standard Guide For Investigating Failure, Deformation And Analysis For Power Transformer And Shunt Reactors

[10]. Mohammed Addul Rahman Uzair, Mohammed Mohiuddin and Mohammed Khaja Shujauddin, Failure Analysis of Power Transformers, International Journal of Emerging Technology and Advanced Engineering, Vol. 3 Issue 9, September 2013

[11]. Jyotirmaya Ghadai and Chinmay Das, Failure of transformers due to Harmoni loads, International Journal of Electrical, Electronic and mechanical controls, Vol. 3, Issue 3, September 2014

[12]. Manish N. Siaha Patel, Parsh Shah, Maulik Dosh and Nishish B, Case Studies of the Transformers Failure Analyses, Jul 5, 2015 